\title{
PERENCANAAN KAWASAN WISATA GUNUNG CABE, KABUPATEN BOGOR
}

\author{
Muhamad Shidqi Shadiqin ${ }^{1)}$, Suryono Herlambang ${ }^{2)}$, Sylvie Wirawati ${ }^{3)}$ \\ 1)Program Studi S1 PWK, Fakultas Teknik, Universitas Tarumanagara, shidqi.shadiqin@gmail.com \\ 2) Program Studi S1 PWK, Fakultas Teknik, Universitas Tarumanagara, s.herlambang@gmail.com \\ 3)Program Studi S1 PWK, Fakultas Teknik, Universitas Tarumanagara, sylvie.wirawati@gmail.com
}

Masuk: 11-08-2020, revisi: 08-09-2020, diterima untuk diterbitkan: 25-09-2020

\begin{abstract}
Abstrak
Kawasan Wisata Gunung Cabe merupakan salah satu kawasan wisata yang dimiliki oleh Perhutani KPH Bogor dan dikelola oleh LMDH Bina Lestari. Kawasan Wisata Gunung Cabe terletak di Desa Cikuda, Kecamatan Parungpanjang, Kabupaten Bogor, dan memilik luas 14 ha. Kawasan wisata ini memiliki ciri khas yaitu pemandangan alam dari atas Puncak Gunung Cabe dengan view bebatuan sehingga pengunjung banyak yang mendatangi Kawasan Wisata Gunung Cabe, selain itu banyak pengunjung yang datang ke kawasan wisata ini untuk berlatih motocross. Kawasan Wisata Gunung Cabe ini memiliki potensi keindahan alamnya, dan kawasan memiliki potensi untuk para komunitas motocross untuk melakukan latihan. Namun pada kawasan wisata ini masih kekurangan dari sarana, prasrana, dan fasilitas wisata sehingga potensi yang ada di area kawasan ini menjadi kurang terlihat. penulis melakukan beberapa analisis seperti analisis lokasi dan tapak, analisis daya tarik wisata, analisis konsep wisata, analisis best practice, dan analisis kebutuhan ruang sehingga menghasilkan usulan dan Perencanaan Kawasan Wisata Gunung Cabe yang direncanakan dengan konsep geowisata.
\end{abstract}

Kata Kunci: Geowisata; Kawasan Wisata Gunung Cabe; Perencanaan; Potensi Wisata

\begin{abstract}
Gunung Cabe Tourism Area is one of the tourism areas owned by Perhutani KPH Bogor and managed by LMDH Bina Lestari. Gunung Cabe Tourism Area is located in Cikuda Village, Parungpanjang District, Bogor Regency, and has an area of 14 ha. This tourist area has a characteristic that is the natural scenery from the top of Mount Chili with rock view so that many visitors come to the Mount Cabe Tourism Area, besides that many visitors come to this tourist area to practice motocross. This Mount Cabe Tourism Area has the potential of its natural beauty, and the area has the potential for motocross communities to do the exercises. But in this tourist area is still lacking of facilities, infrastructure, and tourist facilities so that the potential that exists in the area of this area becomes less visible. The author conducted several analyzes such as site and site analysis, tourist attraction analysis, tourism concept analysis, best practice analysis, and analysis of spatial requirements so as to produce proposals and Planning for the Gunung Cabe Tourism Area planned with the concept of geotourism.
\end{abstract}

Keywords: Geotourism; Gunung Cabe Tourism Area; Planning; Tourism Potential 


\section{PENDAHULUAN}

\section{Latar Belakang}

Pariwisata merupakan berbagai macam kegiatan wisata yang didukung berbagai fasilitas serta pelayanan yang disediakan oleh masyarakat, pengusaha, dan pemerintah (pasal 1 ayat 3 Undang-Undang Nomor 10 Tahun 2009 tentang Pariwisata). Di dalamnya mengandung tiga unsur, yaitu manusia sebagai unsur pelaku kegiatan pariwisata, tempat sebagai unsur fisik yang mencakup kegiatannya, dan waktu sebagai unsur yang dihabiskan dalam perjalanan (Wahab, 1992).

Perum Perhutani Unit III Jawa Barat dan Banten khususnya Kesatuan Pemangkuan Hutan (KPH) Bogor memiliki potensi wisata dengan keragaman bentang alam berupa hutan, pegunungan, keunikan flora dan faunanya, serta ciri khas dari wisata alam yaitu air terjun, goa dan keindahan panorama alam. Salah satu daerah di Kabupaten Bogor pada wisata alam yaitu Wisata Gunung Cabe. Gunung Cabe merupakan salah satu kawasan wisata yang terletak di Desa Cikuda, Kecamatan Parungpanjang, Kabupaten Bogor yang memiliki luas wisata sebesar 14 Ha yang dikelola oleh Lembaga Masyarakat Desa Hutan (LMDH) Binas Lestari. Gunung Cabe ditetepkan sebagai kawasan wisata pada tanggal 4 Mei 2018, dengan Surat/SK Kadivre 0342/043.7/DIVRE JANTEN/PERHUTANI/2018 tanggal 4 Mei 2018 Perihal Penunjukan Lokasi Wisata.

Kawasan Wisata Gunung Cabe ini memiliki potensi keindahan alamnya, dan kawasan memiliki potensi untuk para komunitas motocross untuk melakukan latihan. Namun pada Kawasan Wisata Gunung Cabe belum memiliki konsep pada kawasannya, maka dari itu penulis bertujuan untuk menentukan konsep yang sesuai untuk Kawasan Gunung Cabe, agar kawasan ini memiliki konsep untuk meningkatkan kualitas dan daya tarik pada Kawasan Wisata Gunung Cabe dan pada objek penelitian tersebut penulis akan mengusulkan pembuatan Masterplan agar objek penelitian terlihat lebih tertata dan terawat.

\section{Rumusan Masalah}

Rumusan masalah dari objek Kawasan Wisata Gunung Cabe yaitu kurang sarana, prasrana dan fasilitas pendukung wisata untuk meningkatkan kualitas dari destinasi wisata tersebut. Selanjutnya akses untuk menuju destinasi Kawasan Wisata Gunung Cabe yang masih belum memadai untuk para wisatawan yang ingin berkunjung ke kawasan wisata tersebut.

\section{Tujuan}

Tujuan dari Perencanaan Kawasan Wisata Gunung Cabe yaitu untuk mengetahui sarana, prasrana, fasilitas pendkung, dan area komersil yang dapat mendukung segala aspek yang masih dibutuhkan di Kawasan Wisata Gunung Cabe. Selanjutnya membuat usulan konsep wisata yang tepat untuk Kawasan Wisata Gunung Cabe untuk meningkatkan kualitas dan daya tarik Wisata Gunung Cabe. Tujuan yang terakhir yaitu mengusulkan pembuatan Masterplan agar objek Wisata Gunung Cabe terlihat lebih tertata dan terawat.

\section{KAJIAN LITERATUR}

\section{a. Pariwisata}

Menurut Undang-Undang No 10 Tahun 2010, pariwista merupakan keseluruhan kegiatan yang terkait dengan pariwisata dan bersifat multidimensi serta multidisiplin yang muncul sebagai wujud kebutuhan setiap orang dan negara serta interaksi antara wisatawan dan masyarakat setempat, sesama wisatawan, pemerintah, pemerintah daerah dan pengusaha.

Menurut Oka A. Yoeti (2010:37) pariwisata itu, perjalanan untuk bersenang-senang, kalau tidak mencari kesenangan perjalanan itu tidak dapat disebut sebagai perjalanan wisata. 


\section{b. Wisata}

Menurut Undang-Undang Nomor 10 Tahun 2009 Tentang Kepariwisataaan Bab I pasal 1 dinyatakan bahwa wisata adalah kegiatan perjalanan yang dilakukan oleh seseorang atau sekelompok orang dengan mengunjungi tempat tertentu untuk tujuan rekreasi, pengembangan pribadi, atau mempelajari keunikan daya tarik wisata yang dikunjungi dalam jangaka waktu sementara.

Wisata adalah kegiatan perjalanan atau sebagian dari kegiatan tersebut yang dilakukan secara sukarela serta bersifat sementara untuk menikmati obyek dan daya tarik wisata. Seorang wisatawan berkunjung ke suatu tempat/daerah/Negara karena tertarik oleh sesuatu yang menarik dan menyebabkan wisatawan berkunjung ke suatu tempat/daerah/Negara disebut daya tarik dan atraksi wisata (Mappi, 2001:30).

\section{c. Sarana dan Prasarana Wisata}

Menurut Suwantoro (2004:22) sarana wisata merupakan kelengkapan daerah tujuan wisata yang diperlukan untuk melayani kebutuhan para wisatawan dalam menikmati perjalanannya. Pembangunan sarana wisata di daerah tujuan wisata maupun objek wisata tertentu harus disesuaikan dengan kebutuhan kuantitatif dan kualitatif wisatawan.

Prasarana (infrastructures) adalah semua semua fasilitas yang dapat memungkinkan proses perekonomian berjalan lancar sedemikian rupa, sehingga dapat memudahkan manusia dapat memenuhi kebutuhannya. Prasarana Pariwisata adalah sumber daya alam dan sumber daya manusia yang dibutuhkan oleh para wisatawan dalam melakukan perjalanannya di suatu daerah tujuan wisata, seperti kebutuhan jalan, listrik, air, telekomunikasi, pelayanan kesehatan, terminal/pelabuhan, dan lain sebagainya. (Suwantoro,2004:21)

\section{d. Zonasi Pariwista}

Zoning merupakan suatu sistem pengelompokan unsur-unsur yang mempunyai peranan fungsi yang sama. Sistem ini akan memberikan pengarahan terhadap penentuaan letak massa bangunan secara fisik. Penetapan zoning selalu berorientasi pada aktifitas yang ada. Pembagian zona pada kawasan pariwisata dibagi menjadi beberapa area, yaitu :

a) Zona inti

Zona inti merupakan objek daya tarik wista dimana pada zona inti tidak dapat dilakukan pembagunan yang bertujuan untuk mempertahankan keutuhan dari destinasi wisata.

b) Zona Penyangga

Zona Penyangga merupakan area pendukung/pelindung zona inti.

c) Zona Pengembangan

Zona Pengembangan merupakan area yang diperuntukan bagi pengembangan objek daya tarik wisata, baik itu kepentingan rekreasi, daerah konservasi, lingkungan alam, lansekap budaya, kehidupan budaya tradisional, keagamaan dan kepariwisataan.

d) Zona Penunjang

Zona Penunjang merupakan area yang diperuntukan bagi sarana dan prasara penunjang serta untuk kegiatan komersial dan rekreasi.

\section{e. Geowisata}

Geo Wisata merupakan pariwisata minat khusus yang memanfaatkan potensi sumber daya alam yang ada, seperti potensi dari bentuk bentang alam, batuan, struktur geologi dan sejarah kebumian, sehingga diperlukan peningkatan dalam pemahaman proses fenomena fisik alam. 


\section{f. Motocross}

Menurut Ikatan Motor Indonesia (IMI), motocross merupakan kejuaraan cross country yang dilaksanakan didalam sirkuit dengan menggunakan rintangan - rintangan. Perlombaan in terbuka untuk kendaraan jenis Motocross dan Enduro sesuai dengan buku peraturan teknik FIM (Appendix 01, FIM Motocross Technical Rules).

\section{METODE}

Data yang dikumpulkan selama proses penilitian ini yaitu data fisik dasar Kabupaten Bogor yang terdiri dari batas adminitstrasi, pembagian wilayah per kecamatan, jumlah penduduk, curuh hujan dan iklim. Selanjutnya terdapat data persebaran kawasan wisata yang dimiliki oleh Perhutani KPH Bogor. Data yang diperlukan yang terakhir yaitu data dari Kawasan Wisata Gunung Cabe yang terdiri dari batas wisata, topografi, dan sarana prasrana eksisting yang terdapat di Kawasan Wisata Gunung Cabe.

Dalam penelitian ini terdapat 2 teknik dalam pengumpulan data yaitu teknik pengumpulan data primer dan teknik pengumpulan data sekunder. Teknik pengumpulan data primer dilakukan untuk mengumpulkan data yang berkaitan dengan Kawasan Wisata Gunung Cabe seperti kondisi eksisting, kegiatan eksisting, batas objek studi, sarana dan prasarana yang terdapat di Kawasan Gunung Cabe, topografi, zonasi Kawasan Wisata Gunung Cabe.

Selain itu teknik pengumpulan data sekunder digunakan untuk mengumpulkan data fisik dasar kawasan Kabupaten Bogor seperti batas administrasi, pembagian wilayah per kecamatan, curah hujan, iklim, dan jumlah penduduk. Data tersebut didapat dari BPS Kabupaten Bogor. Selanjutnya terdapat juga data yang berkaitan dengan Kawasan Wisata Gunung Cabe yang didapat dari instansi Perhutani KPH Bogor, seperti SK Penunjukan Lokasi Wisata. Pada penelitian ini dilakukan beberapa analisis yaitu analisis lokasi dan tapak, analisis daya tarik wisata, analisis konsep wisata, analisis best practice, dan analisis kebutuhan ruang yang akan menghasilkan usulan masterplan untuk Kawasan Wisata Gunung Cabe. Terdapat beberapa alat analisis yang digunakan pada penelitian ini yaitu deskriptif, komparatif, SWOT, dan benchmarking.

\section{DISKUSI DAN HASIL}

\section{a. Analisis Lokasi dan Tapak}

Analisis Lokasi

Analisis lokasi bertujuan untuk mengetahui karakteristik dari keadaan sekitar dari lokasi Kawasan Wisata Gunung Cabe untuk mengetahui potensi yang dimiliki oleh Kawasan Wisata Gunung Cabe berdasarkan lokasi dan keadaan eksisting lokasi tersebut. Pembahasan yang akan dibahas pada analisis lokasi, yaitu batas kawasan, aksesibilitas, keterdekatan (proximity) dan lingkungan sekitar tapak.

Batas Kawasan Wisata Gunung Cabe terdiri dari 4 batas yaitu utara, timur, selatan dan barat. Pada batas utara berbatasan dengan jalan setapak menuju Kawasan Wisata Gunung Cabe dan persawahan, selanjutnya pada batas selatan berbatasan dengan salah satu kawasan wisata yaitu Kawasan Wisata Gunung Dago. Pada batas timur dan barat berbatasan dengan hutan dan persawahan milik masyarakat.

Kawasan Wisata Gunung Cabe dapat ditempuh dari beberapa kota/kabupaten yaitu seperti Kota Tangerang, Kota Tangerang Selatan, Kabupaten Tangerang DKI Jakarta, dan Kota Bogor. Aksesibilitas dari DKI Jakarta dapat ditempuh selama 1 jam 22 menit dengan jarak 51,1 km melalui jalan tol, selanjutnya jarak yang dekat dengan Kawasan Wisata Gunung Cabe yaitu Kota Tangerang melalui Via Non Tol dengan jarak 29,3 km dengan waktu tempuh 1 Jam 4 Menit. 
Pada radius $10 \mathrm{~km}$ terdapat beberapa pusat kegiatan seperti terdapat Stasiun ParungPanjang, Stasiun Cicayur, Stasiun Cisauk dan Stasiun Cilejit. Selain itu terdapat pusat pemerintahan yaitu Kantor Kecamatan ParungPanjang dan Kantor Kepala Desa Cikuda. Dan terdapat Puskesmas ParungPanjang dan Klinik Bunda Mulya, pada radius $10 \mathrm{~km}$ terdapat beberapa kawasan wisata lainnya yang letaknya cukup berdekatan antara satu dengan yang lainnya yakni Kawasan Wisata Gunung Dago, Kawasan Wisata Danau Quarry, Kawasan Wisata Curug Rahong, dan Kawasan Wisata Gunung Munara.

Kondisi lingkungan di sekitar tapak didominasi oleh hutan-hutan dan persawahan yang masih asri, terdapat danau buatan dan hunian warga yang berada di lingkungan sekitar tapak. Pada sisi selatan Kawasan Gunung Cabe terdapat Kawasan Wisata Gunung Dago, kedua kawasan wisata tersebut terhubung. Hasil analisis lokasi ini yaitu berupa SWOT dari Kawasan Wisata Gunung Cabe, dan analisis lokasi ini akan menjadi input untuk dilakukannya analisis kebutuhan ruang.

Analisis Tapak

Analisis tapak bertujuan untuk mengetahui karakteristik lahan dalam tapak guna mengetahui potensi yang dimiliki pada Kawasan Wisata Gunung Cabe berdasarkan tapaknya dalam kondisi eksisting. Pada analisis tapak yang akan dibahas, yaitu pembagian dan zonasi kawasan, fasilitas pendukung, kebutuhan sarana dan prasrana.

Pada Kawasan Wisata Gunung Cabe dibagi menjadi beberapa penggunaan lahan, seperti puncak gunung cabe yang memiliki luas 0,47 ha $(3,36 \%)$, warung 0,015 ha $(1,7 \%)$, pos tiket 0,015 ha $(1,7 \%)$ dan hutan 13,23 ha $(94,5 \%)$

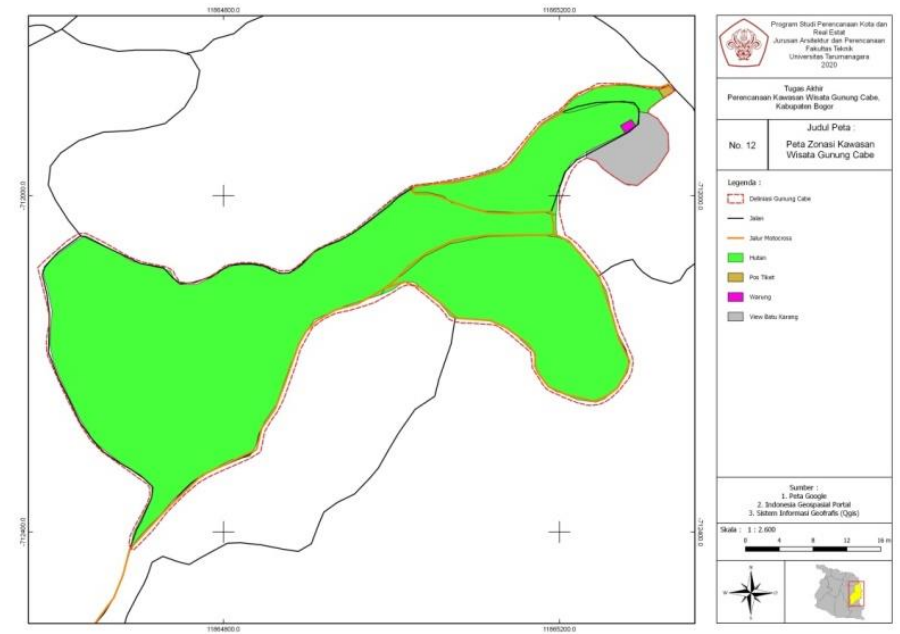

Gambar 1. Peta Objek Studi Kawasan Wisata Gunung Cabe Sumber : Penulis, 2020

Sarana, prasarana dan fasilitas di Kawasan Wisata Gunung Cabe masih belum memenuhi untuk mendukung suatu kawasan wisata. Menurut Lothar A.Kreck dalam bukunya Tourism terdapat beberapa sarana, prasrana dan fasilitas wisata yang harus dipenuhi dalam suatu kawasan wisata yaitu seperti akomodasi, fasilitas penunjang (parkir, toilet), sarana peribadatan, sarana kesehatan, cathering service, perbelanjaan, ATM/Money Changer, keamanan, telekomunikasi, air bersih, aksesibilitas, jaringan listrik (penerangan), dan persampahan. 


\section{b. Analisis Daya Tarik Wisata}

Menurut Yoeti (1996:177) suatu objek wisata atau daya tarik wisata dapat menarik dikunjungi bila memenuhi beberapa syarat yaitu something to see, something to do, dan something to buy. Pada analisis ini dapat disimpulkan bahwa Kawasan Wisata Gunung Cabe memiliki daya tarik berdasarkan teori dari Yoeti (1996:177). Namun pada Kawasan Wisata Gunung Cabe belum memenuhi untuk syarat something to buy dikarenakan pada Kawasan Wisata Gunung Cabe belum terdapat kios souvenir ataupun kios kerajinan masyarakat.

Dapat disimpulkan bahwa Kawasan Wisata Gunung Cabe memiiliki daya tarik wisata jika berdasarkan pada teori Yoeti (1996:177). Namun perlu ditambahkannya kios souvenir ataupun kios kerajinan masyarakat agar para pengunjung dapat berbelanja pada Kawasan Wisata Gunung Cabe, selain itu perlu diadakan tempat makan agar para pengunjung dapat menikmati makanan berat di Kawasan Wisata Gunung Cabe. Hal tersebut dilakukan untuk menambahkan daya tarik wisata pada Kawasan Wisata Gunung Cabe.

\section{c. Analisis Konsep Wisata}

Analisis konsep wisata ini bertujuan untuk menentukan konsep-konsep wisata yang sesuai dengan perencanaan yang akan dilakukan di Wisata Gunung Cabe. Kriteria yang akan diuji pada konsep wisata yaitu daya tarik, kondisi alam, atraksi dan nilai.

Tabel 1. Kriteria Konsep Wisata

\begin{tabular}{llll}
\hline \multicolumn{1}{c}{ Kriteria } & \multicolumn{1}{c}{ Geowisata } & \multicolumn{1}{c}{ Wisata Olahraga (Alam) } & Ekowisata \\
\hline Daya Tarik & Ketinggian/Bentang Alam & Alam, Budaya dan Buatan & $\begin{array}{l}\text { Keindahan } \\
\text { Alam }\end{array}$ \\
\hline Kondisi Alam & Tebing/Kawasan yang & $\begin{array}{l}\text { Berbasis potensi keunikan } \\
\text { lingkungan alam yang ada di }\end{array}$ & Hutan \\
& kemiliki kontur tinggi & Kawasan wisata & \\
\hline Atraksi & Pemandangan Alam & Kegiatan Olahraga & Pelestarian \\
\hline Aspek & Edukasi & Event Olahraga & Konservasi \\
\hline Sumber : Penulis, 2020 & &
\end{tabular}

Dengan metode Lexicographic Ordering, penulis akan memberikan presentase kepentingan terhadap kriteria-kriteria yang selanjutnya akan dikatikan dengan kondisi eksisting, kegiatan eksisting dan perencanaan yang ada di Kawasan Wisata Gunung Cabe.

Tabel 2. Pemilihan Konsep Wisata Berdasarkan Kriteria Konsep Kawasan Wisata

\begin{tabular}{lllll}
\hline \multicolumn{1}{c}{ Konsep } & Daya Tarik & Kondisi Alam & Atraksi & Aspek \\
\hline Ekowisata & & & \\
\hline Geowisata & & & \\
\hline Wisata Olahraga & & & \\
\hline
\end{tabular}

Sumber : Penulis, 2020

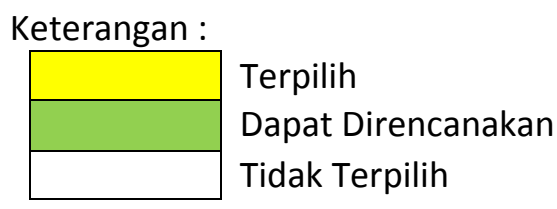

Pada hasil Lexicographic Ordering yang dilihat dari kondisi eksisting dan kegiatan eksisting yang berada di Kawasan Wisata Gunung Cabe dapat disimpulkan bahwa konsep perencanaan dari Kawasan Gunung Cabe akan mengarah pada konsep Geowisata dan Wisata Olahraga 


\section{d. Analisis Best Practice}

Analisis ini bertujuan untuk membahas mengenai objek wisata yang memiliki karakteristik yang mirip dengan Kawasan Wisata Gunung Cabe dan membahas tempat wisata yang sudah ditata dan dikelola dari segi fasilitas dan prasarana yang yang mendukung kawasan wisata. Objek wisata yang akan dijadikan benchmarking adalah Kawasan Wisata Gunung Dago yang berada di Kabupaten Bogor. Selain itu benchmarking untuk sirkuit motocross yang akan dibangun pada Kawasan Gunung Cabe yaitu sirkuit Glen Helen di San Bernardioa, California, United States.

Pada analisis best practice ini tidak hanya membandingkan fasilitas wisata, tetapi mengacu pada kriteria/key success pengembangan untuk kawasan yang berkonsep geowisata. Menurut Hary Hermawan dalam buku nya yang berjudul Geowisata: Perencanaan Pariwisata Berbasis Konservasi, terdapat beberapa prinsip yang menjadikan key success pada suatu kawasan geowisata. Berikut merupakan key success untuk pengembangan kawasan wisata yang berkonsep geowisata :

a) Pada prinsip berbasis geologi yaitu bahwa daya tarik kawasan geowisata berupa kondisi tanah, kandungan mineral, dan jenis-jenis batuan.

b) Pada prinsip berkelanjutan yaitu pada kawasan geowisata harus memperhatikan manfaat suatu kawasan wisata pada kondisi masyarakat lokal dari segi ekonomi, sosial, dan peningkatan kualitas lingkungan. Kegiatan wisata tidak bertentangan dengan kebudayaan masyarakat lokal.

c) Pembangunan kawasan geowisata dibagi menjadi 3 zona yaitu zona preservasi, konservasi, dan zona pemanfaatan.

d) Masyarakat ikut serta dalam pengembangan suatu kawasan geowisata, dan mendapatkan pembagian yang adil dari jasa kegiatan wisata.

e) Mengembangkan fasilitas, sarana dan prasarana serta pelayanan yang prima agar wisatawan yang berkunjung merasa menikmati kunjungannya

Selain penerapan konsep wisata dan key success, beberapa fasilitas dan kegiatan wisata yang berada di benchmarking akan diterapkan di Kawasan Wisata Gunung Cabe. Berikut merupakan kegiatan dan fasilitas pendukung yang akan diterapkan di Kawasan Wisata Gunung Cabe :

Tabel 3. Kegiatan dan Fasilitas Wisata yang Akan Diterapkan

\begin{tabular}{ll}
\hline \multicolumn{1}{c}{ Keigatan Wisata } & \multicolumn{1}{c}{ Fasilitas Wisata } \\
\hline Sepeda Gantung & Warung \\
\hline Menara Pandang (View Deck) & Rumah Makan \\
\hline Sirkuit Motocross & Tempat Penginapan \\
\hline & Camp Area \\
\hline & Tempat Ibadah \\
\hline & Tempat Kesahatan \\
\hline
\end{tabular}

Sumber : Hasil Olahan Penulis, 2020

\section{e. Analisis Kebutuhan Ruang}

Analisis kebutuhan ruang bertujuan untuk mengidentifikasi kebutuhan ruang yang akan dilakukan perencanaan pada Kawasan Wisata Gunung Cabe. Pada analisis ini akan membahas 
tentang kebutuhan ruang untuk perencanaan Kawasan Wisata Gunung Cabe, proyeksi penduduk pada Kawasan Wisata Gunung Cabe, perhitungan untuk luas kebutuhan ruang yang dibutuhkan dan program ruang.

Jumlah dari kebutuhan fasilitas di hitung berdasarkan jumlah pengunjung dan proyeksi pengunjung serta standart pembangunan fasilitas dan standart lintasan motocross di Kawasan Wisata Gunung Cabe. Berdasarkan data yang didapatkan dari pihak Perhutani KPH Bogor bahwa jumlah pengunjung di Kawasan Wisata Gunung Cabe sebanyak 50 pengunjung/minggu. Namun pada hasil survey terakhir penulis sebelum pandemic Covid-19 ini, jumlah pengunjung yang datang ke Wisata Gunung Cabe sekitar 25 orang. Dengan jumlah pengunjung dalam sehari 25 orang, maka dalam satu tahun terdapat 9.125 pengunjung. Untuk menghitung proyeksi pengunjung maka diasumsikan laju pertumbuhan pengunjung sebesar 20\% per tahun. Maka berikut merupakan proyeksi pengunjung 5 tahun ke depan dengan menggunakan rumus metode geometri :

\begin{tabular}{|c|c|}
\hline \multicolumn{2}{|l|}{$\begin{array}{l}\mathrm{Pt}=\mathrm{Po} .(1+\mathrm{r}) \mathrm{t} \\
\text { Keterangan : }\end{array}$} \\
\hline \multicolumn{2}{|c|}{$=$ Jumlah pengunjung pada tahun $\mathrm{t}$} \\
\hline \multicolumn{2}{|c|}{ = Jangka waktu } \\
\hline \multicolumn{2}{|c|}{ = Laju pertumbuhan pengunjung (\%) } \\
\hline \multicolumn{2}{|c|}{ Tabel 4. Proyeksi Pengunjung Kawasan Wisata Gunung Cabe } \\
\hline Tahun & Pengunjung \\
\hline 2019 & 9.125 \\
\hline 2020 & 10.950 \\
\hline 2021 & 13.140 \\
\hline 2022 & 15.768 \\
\hline 2023 & 18.922 \\
\hline 2024 & 22.706 \\
\hline
\end{tabular}

Sumber : Penulis, 2020

Pada perhitungan kebutuhan ruang fasilitas yang akan dibangun di Kawasan Wisata Gunung Cabe, maka jumlah pengunjung yang digunakan diambil pada proyeksi pengunjung pada tahun 2024 yaitu dengan jumlah pengunjung perhari pada tahun 2024 yaitu 63 pengunjung perhari.

Dalam melakukan penataan kawasan wisata maka diperlukan pembagian zona perencaan. Pembagian zona di Kawasan Wisata Gunung Cabe dibagi menjadi 4 yattu :

a) Zona Inti

Zona inti ini merupakan kawasan yang berfungsi untuk mempertahankan keutuhan dari Puncak Gunung Cabe yang terdapat batu karang sebagai view untuk para pengunjung. Pada Kawasan Wisata Gunung Cabe memiliki zona inti seluas 0,47 ha.

b) Zona Penyangga

Zona penyangga pada Kawasan Wisata Gunung Cabe memiliki luas 2,3 ha yang memiliki fungsi sebagai mendukung atau melindungi zona inti atau zona pendukung zona inti. Zona ini menjadi suatu tanda bahwa seorang wisatawan akan segera memasuki suatu kawasan inti dari suatu atraksi wisata di lokasi tertentu.

c) Zona Pengembangan

Zona pengembangan memiliki fungsi sebagai area yang diperuntukan bagi pengembangan potensi Objek Destinasi Tujuan Wisata (ODTW) baik itu untuk kepentingan rekreasi, atau untuk kegiatan-kegiatan wisata. Zona pengembangan di Kawasan Wisata Gunung Cabe 
memiliki luas sebesar 2,9 ha.

d) Zona Pelayanan

Zona pelayanan memiliki fungsi sebagai area yang diperutukkan bagi penyiapan pelayanan dimana seluruh aktifitas fasilitas pendukung dikelompokkan untuk wisatawan yang berkunjung ke lokasi wisata, dan pada area ini terdapat sarana dan prasarana penunjang serta kegiatan komersil seperti akomodasi, tempat makan dan lain sebagainya. Zona pelayanan ini memiliki luasan 8,33 ha. (Hermawan \& Brahmanto, 2017)

Tabel 5. Rencana Kebutuhan Ruang Berdasarkan Zona Wisata di Gunung Cabe

\begin{tabular}{|c|c|c|c|c|}
\hline \multirow{2}{*}{ Zona } & \multirow{2}{*}{ Fasilitas } & \multicolumn{2}{|c|}{ Luas } & \multirow{2}{*}{ Sumber } \\
\hline & & $\left(m^{2}\right)$ & (Ha) & \\
\hline Inti & Menara Padang & 70 & 0,007 & Kementrian Pariwisata \\
\hline \multicolumn{2}{|c|}{ Kebutuhan Lahan Zona Inti } & 70 & 0,007 & \\
\hline \multirow{6}{*}{ Penyangga } & Pusat Informasi/TIC & 112 & 0,011 & Kementrian Pariwisata \\
\hline & Area Parkir & 328 & 0,033 & Kementrian Pariwisata \\
\hline & Mushola & 164 & 0,016 & SNI \\
\hline & Toilet & 141 & 0,014 & $\begin{array}{c}\text { Standart Arsitektur } \\
\text { Ernst Neufert }\end{array}$ \\
\hline & ATM & 10 & 0,001 & Asumsi Penulis \\
\hline & Theme Park & 5.681 & 0,568 & Asumsi Penulis \\
\hline \multicolumn{2}{|c|}{ Kebutuhan Lahan Zona Penyangga } & 6.436 & 0,643 & \\
\hline \multirow{4}{*}{ Pengembangan } & Sirkuit Motocross & 16.841 & 1,6481 & $\begin{array}{c}\text { Ikatan Motor } \\
\text { Indonesia (IMI) }\end{array}$ \\
\hline & Toilet & 141 & 0,014 & $\begin{array}{c}\text { Standart Arsitektur } \\
\text { Ernst Neufert }\end{array}$ \\
\hline & Ruang Ganti & 123 & 0,123 & $\begin{array}{c}\text { Standart Arsitektur } \\
\text { Ernst Neufert }\end{array}$ \\
\hline & ATM & 10 & 0,001 & Asumsi Penulis \\
\hline \multicolumn{2}{|c|}{ Kebutuhan Lahan Zona Pengembangan } & 17.115 & 1,711 & \\
\hline \multirow{9}{*}{ Pelayanan } & Gueshouse & 3.177 & 0,318 & Asumsi Penulis \\
\hline & Glamping Area & 6.293 & 0,629 & Asumsi Penulis \\
\hline & Kios Souvenir & 3.924 & 0,392 & Kementrian Pariwisata \\
\hline & Restauran & 1.605 & 0,16 & Kementrian Pariwisata \\
\hline & Warung & 1.912 & 0,191 & Kementrian Pariwisata \\
\hline & Gazebo & 100 & 0,010 & $\begin{array}{c}\text { Standart Arisitektur } \\
\text { Ernst Neufert }\end{array}$ \\
\hline & Area Parkir & 1.942 & 0,194 & Kementrian Pariwisata \\
\hline & Pusat Infromasi/TIC & 112 & 0,011 & Kementrian Pariwisata \\
\hline & Jembatan Gantung & 1.610 & 0,161 & Asumsi Penulis \\
\hline \multicolumn{2}{|c|}{ Kebutuhan Lahan Zona Pelayanan } & 20.675 & 2,064 & \\
\hline \multicolumn{2}{|c|}{ Total Kebutuhan Ruang } & 44.296 & 4,429 & \\
\hline \multicolumn{2}{|c|}{ Presentase Kebtuhan Ruang } & & $31,6 \%$ & \\
\hline
\end{tabular}

Sumber : Hasil Olahan Penulis, 2020

Konsep penataan yang akan diterapkan di Kawasan Wisata Gunung Cabe yaitu konsep geowisata dan wisata olahraga (sport tourism), pemilahan konsep wisata ini berdasarkan kondisi eksisting yang berada di Kawasan Wisata Gunung Cabe. Konsep geowisata ini memiliki prisnip dasar yaitu berbasis geologi (geologically based), berkelanjutan (suistanable), bersifat infromasi geologi (geologically infromative), bermanfaat secara lokal (locally benefit), dan Kepuasan Pengunjung (tourist satisfaction).

Rencana penggunaan lahan yang akan dilakukan di Kawasan Wisata Gunung Cabe akan disesuaikan dengan keadaan topografi yang ada di Kawasan Wisata Gunung Cabe dan tetep mempertahankan kualitas alam pada area Gunung Cabe. 
Tabel 6. Rencana Pengunaan Lahan Pada Penataan Wisata Gunung Cabe

\begin{tabular}{|c|c|c|c|}
\hline No & Jenis Penggunaan Lahan & Luas (Ha) & Presentase (\%) \\
\hline \multirow[t]{9}{*}{1} & Fasilitas & & \\
\hline & - Gazebo & 0,010 & \\
\hline & - Menara Pandang & 0,007 & \\
\hline & - Pusat Informasi/TIC & 0,022 & \\
\hline & - Area Parkir & 0,227 & \\
\hline & - Toilet dan Ruang Ganti & 0,040 & \\
\hline & - ATM & 0,002 & \\
\hline & - Mushola & 0,016 & \\
\hline & Total Luas Fasilitas & 0,324 & $2,2 \%$ \\
\hline \multirow[t]{8}{*}{2} & Komersil & & \\
\hline & - Warung & 0,191 & \\
\hline & - Restoran & 0,16 & \\
\hline & - Kios Souvenir & 0,392 & \\
\hline & - Sirkuit Motocross & 1,711 & \\
\hline & - Theme Park & 0,568 & \\
\hline & - Jembatan Gantung & 0,161 & \\
\hline & Total Luas Komersil & 3,183 & $22,7 \%$ \\
\hline \multirow[t]{4}{*}{3} & Penginapan & & \\
\hline & - Guesthouse & 0,318 & \\
\hline & - Glamping Area & 0,629 & \\
\hline & Total Luas Penginapan & 0,947 & $6,7 \%$ \\
\hline \multirow[t]{2}{*}{4} & Hutan & 9,546 & $68,4 \%$ \\
\hline & Total & 14 & $100 \%$ \\
\hline
\end{tabular}

Sumber : Penulis,2020

Perencanaan bangunan yang akan direncakan di Kawasan Wisata Gunung Cabe tetap menggunakan material yang tidak merusak lingkungan dan disesuaikan dengan kebutuhan pengunjung. Untuk menambahkan daya tarik di Kawasan Wisata Gunung Cabe maka untuk konsep bangunan untuk guesthouese menggunakan konsep rumah sunda.

Rencana jaringan jalan utama pada Kawasan Wisata Gunung Cabe direncanakan dengan lebar ROW sebesar 10 meter sehingga dapat dilalui dengan oleh pengunjung yang membawa sepeda motor, mobil ataupun bus wisata. Rencana jaringan setapak pada Kawasan Wisata Gunung Cabe direncanakan menggunakan jalur Boardwalk yang merupakan jalur pejalan kaki yang biasanya dibuat dari kayu. Boardwalk dapat digunakan untuk membantu pejalan kaki menempuh medan yang sulit seperti di kawasan hutan, sungai, pantai dan lain sebagainya. Penggunaan Boardwalk sanagat mendukung untuk menjaga kelestarian dan keutuhan alam yang berada di Kawasan Wisata Gunung Cabe.
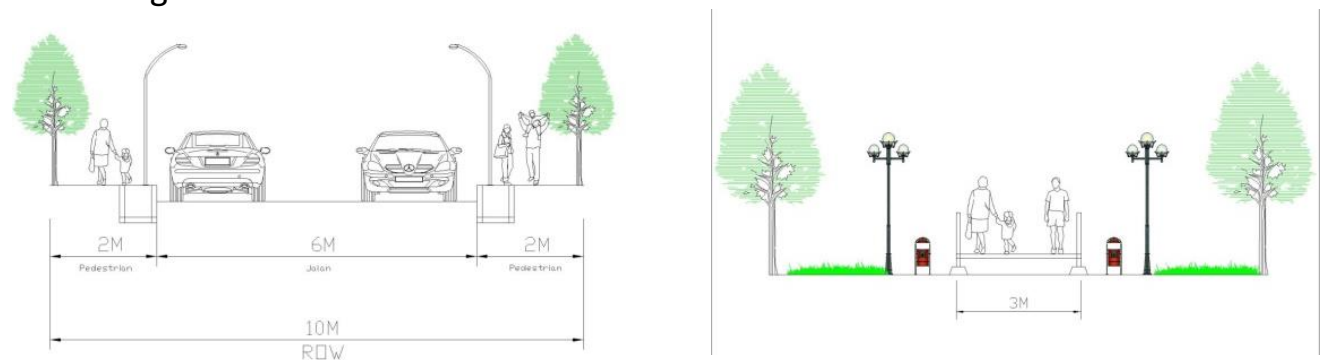

Gambar 2. Potongan Rencana Jalan Utama dan Boardwalk Sumber : Penulies, 2020

Masterplan dari Kawasan Wisata Gunung Cabe terdiri dari area komersial, area penginapan, area 
sirkuit motocross, area wahana tambahan seperti themepark dan area jembatan gantung. Serta menambahkan gazebo, lampu penerangan, parkir, toilet, dan atm. Penambahan fasilitas tersebut diharapkan dapat meningkatkan kualitas dari Kawasan Wisata Gunung Cabe. Berikut merupakan masterplan pada Kawasan Wisata Gunung Cabe dengan menggunakan konsep geowisata:
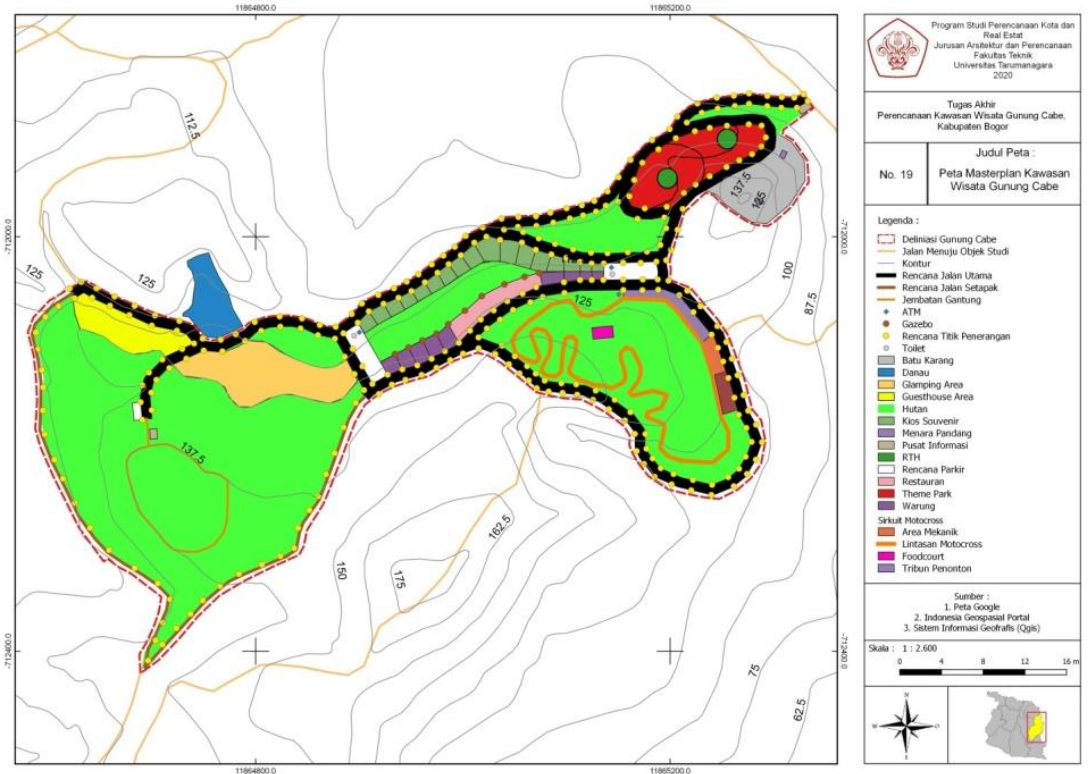

Gambar 3. Masterplan Kawasan Wisata Gunung Cabe Sumber : Penulis,2020

\section{KESIMPULAN DAN SARAN}

\section{Kesimpulan}

Berdasarkan hasil keseluruhan penulisan Tugas Akhir ini mengenai Perencanaan Kawasan Wisata Gunung Cabe yang terletak di Kabupaten Bogor, maka didapatkan beberapa poin kesimpulan sebagai berikut :

a. Dengan melihat kondisi eksisting yang ada di Kawasan Wisata Gunung Cabe, maka pada perencanaan akan diusulkan konsep wisata yaitu konsep geowisata dan wisata olaharaga. Pemilihan konsep wisata geowisata dan wisata olahraga ini dilakukan untuk meningkatkan kualitas dan daya tarik wisata Gunung Cabe.

b. Perencanaan yang akan dilakukan pada Kawasan Wisata Gunung Cabe akan dibagi menjadi 4 zona yaitu zona inti, zona penyangga, zona pengembang, dan zona pelayanan. Pembangunan sarana, prasrana dan fasilitas di Kawasan Wisata Gunung Cabe akan disesuaikan dengan fungsi dari masing-masing zona.

c. Pembuatan Masterplan pada Kawasan Wisata Gunung Cabe ini dilihat dari kebutuhan ruang yang dibutuhkan pengunjung pada Kawasan Wisata Gunung Cabe, dan pembuatan Masterplan ini juga diusulkan agar Kawasan Wisata Gunung Cabe lebih tertata dan terawat.

\section{Saran}

Dalam penelitian ini, penulis memberikan saran kepada Perhutani KPH Bogor, LMDH Bina Lestari dan masyarakat sekitar Kawasan Wisata Gunung Cabe yaitu masyarakat Desa Cikuda. Berikut merupakan sarana dan usulan bagi Perencanaan di Kawasan Wisata Gunung Cabe :

a. Perhutani KPH Bogor

a) Perhutani KPH Bogor sebagai pemilik Kawasan Wisata Gunung Cabe harus melakukan komunikasi yang baik kepada pihak pengelola LMDH Bina Lestara dan masyarakat Desa 
Cikuda mengenai perencanaan atau penataan pada Kawasan Wisata Gunung Cabe.

b) Ikut serta dalam perencanaan pada Kawasan Wisata Gunung Cabe nantinya.

c) Memastikan agar masyarakat sekitar ikut berpartisipasi didalam perencanaan atau penataan yang akan dilakukan di Kawasan Wisata Gunung Cabe.

d) Perhutani KPH Bogor dapat membantu untuk mencari pihak ketiga atau investor yang ingin investasi dalam perencanaan atau penataan yang akan dilakukan di Kawasan Wisata Gunung Cabe.

b. LMDH Bina Lestari

a) Melakukan komunikasi yang baik dengan warga sekitar, agar warga sekitar dapat merasakan dampak yang baik dari Kawasan Wisata Gunung Cabe.

b) Memastikan agar masyarakat sekitar ikut serta dalam penataan yang akan dilakukan di Kawasan Wisata Gunung Cabe.

c) Melakukan pengecekan fasilitas yang ada di Kawasan Wisata Gunung Cabe.

d) Menjaga Kawasan Wisata Gunung Cabe agar tidak terjadi vandalisme yang dilakukan oleh oknum yang tidak bertanggung jawab dan mengingatkan agar para pengunjung untuk menjaga kebersihan di Kawasan wisata Gunung Cabe.

e) Melakukan kerja sama dengan para komunitas motocross dalam melakukan pembangunan sirkuit motocross agar sirkuit tersebut nyaman saat digunakan oleh para komunitas motocross dan agar sirkuit tersebut sesuai dengan standart yang ada.

c. Masyarakat

a) Adanya komunikasi yang baik antara masyarakat dengan pemilik dan pengelola Kawasan Wisata Gunung Cabe yaitu Perhutani KPH Bogor, dan LMDH Bina Lestari.

b) Ikut berperan serta dalam perencanaan dan pembangunan yang akan dilakukan di Kawasan Wisata Gunung Cabe.

c) Masyarakat dapat memberikan masukan kepada LMDH Binas Lestar dan Perhutani KPH Bogor mengenai pembangunan atau penataan yang akan dilakukan kedepannya.

\section{REFERENSI}

Hermawan, H., \& Brahmanto, E. (2017). Geowisata: Perencanaan Pariwisata Berbasasi Konservasi. Bandung: NEM.

Ikatan Motor Indonesia. (2017). Peraturan Dasar Olahraga Motor. Jakarta.

Peraturan Menteri Pariwisata Republik Indonesia Nomor 3 Tahun 2018. Jakarta : Menteri Pariwista Republik Indonesia

Pendit, N. (1999). Ilmu Pariwisata Sebuah Pengantar Perdang. Dalam N. Pendit, Ilmu Pariwisata Sebuah Pengantar Perdang. Jakarta: PT Pradnya Paramitha.

Pitana, I G, \& Gayatri, P G. (2005). Sosiologi Pariwisata. Yogyakarta: Andi.

Spline, J. (1994). Pariwisata Indonesia, Siasat Ekonomi dan Rekayasa Kebudayaan. Yogyakarta: Kanisisus.

Suwantoro, G. (2004). Dasar-Dasar Pariwisata. Yogyakarta: Andi.

Swarbrooke. (1994). Pengembangan Pariwisata. Jakarta: Gramedia Pustaka Utama.

Undang Undang tentang Kepariwisataan, UU No. 9 Tahun 1990. Jakarta: Menteri Sekretaris Negara.

Undang Undang tentang Kepariwisataan, UU No. 10 Tahun 2009. Jakarta: Direktorat Jenderal Hukum dan HAM.

Yoeti, O. A. (1996). Pengantar IImu Pariwisata. Bandung: Angkasa Bandung.

Yoeti, O. A. (2008). Perencanaan dan Pengembangan Pariwisata. Jakarta: PT. Pradnya Paramita. 